\title{
REFUGIADOS NORTE-COREANOS: ADAPTAÇÃO E REALOCAÇÃO SOCIAL NA COREIA DO SULL ${ }^{1}$
}

\author{
NORTH-KOREAN REFUGEES: ADAPTATION AND SOCIAL REALLOCATION IN \\ SOUTH KOREA
}

\author{
Bruna Leal Barcellos \\ Mestranda em Políticas Públicas, UFPR \\ Bacharela em Relações Internacionais pela UNINTER. Curitiba, Paraná. \\ bl-barcellos@hotmail.com. \\ Aline de Oliveira \\ Mestranda em Marketing, Universidade de Lisboa \\ Bacharela em Relações Internacionais pela UNINTER. Curitiba, Paraná. \\ alinedeoliveira13@gmail.com
}

\section{Resumo}

A comunidade internacional possui hoje uma responsabilidade no que tange aos direitos humanos, e dentro desse conceito, aos direitos dos refugiados. Os refugiados representam um grupo de indivíduos que devido a condições domésticas de seu país de origem, devem deixar seu território em busca de abrigo em outro local ou comunidade. Compreendendo a contemporaneidade do tema, o presente artigo buscará fazer uma análise focada nos refugiados norte-coreanos, mais especificamente, como ocorre a realocação social na Coreia do Sul. A partir de uma breve análise sobre a criação de políticas públicas e compreensão da Teoria da Interdependência Complexa, o artigo irá analisar o número de refugiados norte-coreanos que tiveram como destino a Coreia do Sul, assim como, os programas sul-coreanos para recebimento desses refugiados. A partir de uma análise bibliográfica e qualitativa, assim como, a leitura de dados quantitativos, o artigo apresenta uma análise que demonstra que, ainda que com políticas aplicadas para esse grupo, o Estado sul-coreano não consegue atingir sua própria população em relação a prepará-la para o recebimento desses indivíduos, garantindo que o impacto das diferenças culturais e sociais não interfira na total realocação dos refugiados norte-coreanos.

Palavres Chave: Refugiados; Coreia do Sul; políticas públicas; norte-coreanos.

\section{Abstract}

The international community has a responsibility to human rights, and within that concept, to the rights of refugees. Refugees represent a group of individuals who, due to factors beyond their control, must leave their territory in search of shelter in another location or community. Understanding the contemporaneity of the theme, the present article will seek to make a focused analysis of the North Korean refugees, more specifically, of their social reallocation in South Korea. From a brief analysis on the creation of public policies and understanding of Theory of Complex

1 "O presente trabalho foi realizado com apoio da Coordenação de Aperfeiçoamento de Pessoal de Nível Superior - Brasil (CAPES) - Código de Financiamento 001"

"This study was financed in part by the Coordenação de Aperfeiçoamento de Pessoal de Nível Superior - Brasil (CAPES) - Finance Code oo1" 
Interdependence, the article will analyze the number of North Korean refugees in South Korea, as well as South Korean programs to receive these refugees. From a bibliographical and qualitative analysis, as well as the reading of quantitative data, the article presents an analysis that demonstrates that, although with policies applied to refugees, the South Korean state cannot reach its own population to prepare it for the reception of these individuals by ensuring that the impact of cultural and social differences does not interfere with the full reallocation of North Korean refugees.

Key words: Refugee; South Korea; public policy; north-korean.

\section{INTRODUÇÃO}

Segundo definição do Alto Comissariado das Nações Unidas para os Refugiados (ACNUR), refugiados são as pessoas que deixam seus países devido às perseguições relacionadas à raça, religião, nacionalidade, grupo social, opnião política, ou devido às violações dos direitos humanos e conflitos armados (ACNUR, 2018). O ACNUR surgiu como uma ferramenta de proteção aos refugiados que, devido ao seu crescimento, passou a ser reconhecida pela comunidade internacional e se tornar alvo de políticas voltadas para realocação e proteção de pessoas em situação de refúgio (MILESI, 2003, p. 13). Todavia, não foi criada uma solução para o problema dos refugiados, ou seja, não foi elaborada uma forma de evitar que pessoas precisassem sair de seus países de origem, apenas tentou-se lidar com um problema existente e cada vez mais frequente.

O desenvolvimento da sociedade moderna, o avanço econômico e as novas redes de relações internacionais não impediram que conflitos, ou até mesmo fatores ambientais, causassem a saída de povos de suas terras. O ACNUR apresenta dados que demonstram que existem hoje mais de 19 milhões de pessoas que fazem parte do grupo de refugiados em todo o mundo, sendo que mais de 3 milhões de indivíduos ainda procuram asilo e quase 40 mil desses indivíduos deixaram seu país devido à conflitos (ACNUR, 2018). Esses dados ressaltam ainda mais a importância de ações dos estados em acolher esses refugiados e garantir seus direitos e proteção.

Entretanto, ocorre de fato o cumprimento do compromisso estatal para com os refugiados? A presente análise buscará identificar isso no caso do Estado da Coreia do Sul, trazendo a problemática dos refugiados não somente serem do país vizinho em aspectos geográficos, mas também, de compartilharem uma herança histórica que sofreu com a ruptura provocada pela guerra da Coreia.

Para auxiliar na construção bibliográfica sobre esse objeto, o presente artigo irá analisar as políticas implementadas pelo Estado sul-coreano no que concerne o recebimento e realocação do refugiado norte-coreano. Dividido em quatro seções, o artigo irá primariamente apresentar conceitos e teorias relacionadas as políticas públicas, interdependência complexa e autonomia estatal. Nesse capítulo também serão abordadas as definições de refugiados estabelecidas pelo ACNUR. Como próximo tópico serão também abordados os números de refugiados norte-coreanos na Coreia do Sul a partir de dados 
coletados no site do Ministro da Unificação da Coreia do Sul em auxílio a uma base bibliográfica. Logo após, o artigo apresentará quais os programas de acolhimento aos refugiados norte-coreanos estabelecidos pela Coreia do Sul.

Por fim, como última parte do artigo, conclui-se a partir da análise proposta que, ainda que o Estado sul-coreano implemente políticas ao nível técnico para auxiliar a introdução dos norte-coreanos no sistema sul-coreano, o mesmo acaba por não conseguir atingir a sociedade em um todo com suas políticas. Notou-se a partir de uma revisão bibliográfica e leitura de dados que grande parte dos refugiados nortecoreanos tem problemas em se sentir integrado na cultura do seu novo país, assim como, os sul-coreanos têm dificuldade de compreender as origens e diferenças dos norte-coreanos.

\section{TEORIAS E CONCEITOS - POLÍTICAS PÚBLICAS, INTERDEPENDÊNCIA COMPLEXA E OS REFUGIADOS}

Considerando que o presente artigo busca analisar as políticas públicas implementadas pelo estado sul-coreano em relação aos refugiados norte-coreanos, identifica-se a necessidade de esclarecer alguns conceitos e teorias que nortearão a pesquisa. Inicialmente, a fim de proporcionar uma base para compreensão das políticas sul-coreanas de acolhimento aos refugiados, será introduzida uma base teórica sobre o que são as políticas públicas e o que elas representam.

Compreende-se que a criação de políticas públicas para refugiados se faz de suma importância para garantir os direitos básicos que o indivíduo necessita nesse novo território. Sendo assim, o Estado teria um papel fundamental de não somente acolher esses refugiados, mas também de identificar e adicionar a sua agenda de políticas públicas questões pertinentes ao assunto a fim de elaborar programas e projetos de acolhimento para esse grupo.

Não obstante, o papel exclusivo, ou não, do Estado na criação de políticas públicas ainda é fonte de debate. Secchi (2012) levanta algumas questões sobre a origem de tais políticas. Afinal, somente 0 Estado as cria? Somente o que o Estado faz é política ou sua inércia, a não tomada de decisão, também pode ser considerada uma política pública?

Em relação ao primeiro ponto, Secchi aponta para a existência de duas abordagens nas políticas públicas: a estatista e a multicêntrica. A estatista tem como ponto central de estudo o Estado, considerando-o como ator principal de criação das políticas públicas e observando a atuação de atores não estatais como somente de influência, mas não de decisão. Já a abordagem multicêntrica exerce mais uma análise sobre o que é ou não privado ao invés do que é, ou não, estatal. Nessa abordagem, a visão de um problema - ou do que é um problema — surge naqueles diretamente envolvidos podendo esses serem membros da própria sociedade, por exemplo (SECCHI, 2012, 02). 
Dye em seu livro cita que "política pública é tudo o que o governo decide fazer ou não fazer" (DYE, 2013, p. 03). É a partir da definição de Dye que Secchi parte para um debate sobre como a não ação do Estado acaba também sendo considerada como uma política pública. Para Secchi, a não ação do governo para determinados temas pode apresentar uma posição específica que esse mesmo tem para o problema em particular (SECCHI, 2012, 03). No caso aqui analisado, se o estado sul-coreano não promovesse políticas de acolhimento aos refugiados, tal inação também poderia ser analisada, já que representaria uma posição do governo em relação ao tema.

Smith (1976) também traz a tona a inação do Estado como sendo uma parte da política, destacando a ideia de que a análise dessa mesma não deve somente focar nas mudanças, mas também nas inações (SMITH, 1976, p. 13). A fala de Smith pode também entrar em um debate sobre visões e conceitos sobre o que é a política e como defini-la e enxergá-la. Hill (2005) explora algumas das definições mais utilizadas ou amplamente difundidas sobre o tema, apresentado a interpretação de Easton que vê a política como uma rede de decisões e ações com valores. Essa definição, de certa forma, difere da de Jenkins que observa a política como um conjunto de decisões correlacionadas que auxiliam na definição de objetivos e as formas de os alcançá-los (HILL, 2005, p. 07).

Essas diferentes interpretações e visões sobre o que é política e política pública acompanham também diferentes formas de abordagem sobre o tema. Não obstante, um ponto levantado por Celina Souza (2006) deve ser mencionado: o caráter holístico que essas diferentes formas de abordagem tem em comum como fruto de um campo multidisciplinar.

\footnotetext{
Assim, do ponto de vista teórico-conceitual, a política pública, em geral, e a política social em particular são campos multidisciplinares, e seu foco está nas explicações sobre a política pública e seus processos. (...) As políticas públicas repercutem na economia e nas sociedades, daí por que qualquer teoria da política pública precisa também explicar as inter-relações entre Estado, política, economia e sociedade. (SOUZA, 2012, p. 25)
}

A fala de Celina Souza se faz importante principalmente no que tange a afirmação da correlação entre estado e sociedade. É reafirmada a importância que as ações de tem na realidade do outro e é fortalecida a ideia de que a análise de uma política pública é mais que a explicação de um objeto ou ator, é também uma análise da relação entre diferentes atores.

A análise de políticas públicas pode adotar diferentes abordagens, buscando analisar a relação entre dois atores em particular, ou até mesmo analisar a criação de uma política pública em específico. Esse último exemplo se enquadra em uma análise feita a partir do modelo do ciclo de políticas públicas (policy cicle). O ciclo de Políticas Públicas é um processo de formulação de políticas compreendido nos seguintes passos: identificação do problema, formulação da agenda, formulação de alternativas, tomada de decisão, implementação, avaliação e extinção (SECCHI, 2012, p. 33). 
Esse modelo foi em princípio concebido por Laswell, em 1956, na busca por construir uma ciência política prescritiva e multidisciplinar tendo em início mais estágios para descrever o processo da política, sendo esses: o entendimento (ou reconhecimento do problema/desafio), promoção, prescrição, invocação, aplicação, término e avaliação (JANN, WEGRICH, 2007, p. 43). Ainda que o modelo tenha obtido sucesso, conforme deLeon (1999) cita, o ciclo de políticas também é cercado de críticas sobre sua real eficácia na análise de políticas públicas. Um dos críticos a esse modelo seria Sabatier que aponta problemas como a não praticidade de sua aplicação em análises empíricas, não estabelecendo como um estágio da política leva a outro e não considerando a relação entre atores (DELEON, 1999, p. 24).

Não obstante, o modelo do ciclo se mostra positivo para a presente análise devido à base que proporciona para a compreensão dos momentos de uma política. A ideia de avaliação também se faz pertinente a esse artigo. Dye (2013) cita que o impacto identificado em uma avaliação de política pode ser considerado através de seus efeitos simbólicos, onde, ainda que a política não tenha o resultado esperado, a tomada de decisão sozinha já é válida para a sociedade (DYE, 2013, p. 65). Deve-se, entretanto, pontuar que o presente artigo não pretende proceder como uma avaliação de política ao reconhecer a necessidade de uma abordagem mais empírica para tal. A exploração da teoria de políticas públicas se faz de forma a proporcionar uma informação introdutória ao leitor sobre o que de fato são essas políticas, sem sair do caráter descritivo a partir da leitura qualitativa de dados quantitativos aqui expostos.

Seguindo a discussão sobre interações entre atores, tende-se a ver a interação direta entre atores sociais e estatais no estabelecimento de políticas, onde as necessidades da sociedade podem evoluir a ponto de se tornar um objeto ou problema que requer uma política para solucioná-lo (MENY, 1992, p. 110). Essa tendência na observação das políticas públicas como sendo criadas a partir de uma vontade geral da sociedade vai em direção contrária a de perspectivas mais funcionalistas e estruturalistas que observam as decisões do Estado como favoráveis a determinados grupos de interesse dentro da sociedade. Skocpol (1985) traz para a mesa de debates uma nova ideia: a de um Estado autônomo. Segundo a autora, o Estado, ao contrário de outros pensamentos, poderia sim tomar decisões por conta própria, sem necessariamente sofrer pressões de determinado grupo, e sem que tais decisões sejam uma demanda social (SKOCPOL, p. 09, 1985).

O debate sobre a independência do Estado pode também ser encontrado nos escritos de Marx e Engels conforme Hamilton (1982) cita. Segundo os autores, existira um interesse estatal separado do interesse coletivo em um cenário onde o Estado buscaria construir sua própria identidade, se tornando uma força independente em situações específicas (HAMILTON, 1982, p. 06). Skocpol (1985) cita a relação entre autonomia do Estado e sua participação no cenário internacional, argumentando que as condições desse cenário externo podem servir para que líderes políticos escolham caminhos que nem sempre seguem, ou sequer são reconhecidos pelas suas forças sociais internas. Nessa visão de estado autônomo, 
Skocpol chama a atenção para a possibilidade de duas abordagens: a primeira é a de que o estado é uma organização utilizada por oficiais que buscam alcançar objetivos, tendo seu sucesso variado de acordo com os recursos disponíveis. A segunda abordagem interpreta o estado como uma organização que toma decisões que influenciam as políticas para todos os grupos da sociedade (SKOCPOL, 1985, p. 28).

Ambas as visões apresentam uma interpretação do Estado como ator, nesse ponto identifica-se o ator como aquele que age, toma uma decisão (DENTE, 2014). Essa ação pode ou não ser uma representação dos anseios internos de sua sociedade, ou uma representação dos fluxos de informação e comunicação de um cenário internacional do qual o estado faria parte.

Essa concepção do estado como ator com certa autonomia para a tomada de decisões possibilita uma maior compreensão de políticas públicas e ações nem sempre em demandas pela sociedade interna. Entretanto, tal concepção de autonomia não deve ignorar a existência e influência de grupos sociais ou instituições internacionais e também não deve eliminar o fenômeno da globalização. O Estado ainda que convivendo com esses grupos e organizações preserva parte da sua autonomia (SOUZA, 2002, p. 06), mas sem negar sua existência e importância no cenário global. A relevância em relação a essa visão de autonomia se mostra importante para a análise ao compreender que as políticas para refugiados não partiram de uma demanda social interna, mas sim, de certa forma, até mesmo contrária aos anseios de grande parte da população sul-coreana, conforme será debatido no capítulo seguinte.

Retomando a temática conceitual e teórica, ao estabelecer essa conexão entre atores presentes no âmbito internacional cabe para o presente artigo uma análise sobre o Estatuto para os refugiados, visto que esse mesmo teve uma influência no modo como diferentes estados passaram a compreender e formular políticas para os membros desse grupo.

A Convenção de 1951 formalizou a importância sobre a problemática dos refugiados adotando um Estatuto que viria a garantir direitos àqueles que, por algum motivo, tiveram que abandonar seu país de origem. As definições e compreensões de quem eram os refugiados foram se alterando conforme 0 passar dos anos. Um exemplo é a criação do Protocolo de 1967 que expandia a proteção para todos os refugiados e não somente para aqueles que haviam sido de alguma forma atingidos até o ano de 1951. Apresenta-se a definição de refugiado como:

Art. $1^{\circ}$-Definição do termo "refugiado"

A. Para os fins da presente Convenção, o termo "refugiado" se aplicará a qualquer pessoa: (...) 2) Que, em conseqüência dos acontecimentos ocorridos antes de $1^{\circ}$ de janeiro de 1951 e temendo ser perseguida por motivos de raça, religião, nacionalidade, grupo social ou opiniões políticas, se encontra fora do país de sua nacionalidade e que não pode ou, em virtude desse temor, não quer valer-se da proteção desse país, ou que, se não tem nacionalidade e se encontra fora do país no qual tinha sua residência habitual em conseqüência de tais acontecimentos, não pode ou, devido ao referido temor, não quer voltar a ele. 
As mudanças nas definições criaram a necessidade de novas reformulações e novos protocolos que buscavam a proteção desse grupo. Caberia ao ACNUR não somente promover instrumentos de proteção aos refugiados, mas também de supervisionar os impactos e efeitos de tais instrumentos (ACNUR, 2018, p. 01).

A necessidade de um órgão específico de criação e acompanhamento de políticas com relação aos refugiados se da não somente pelo crescimento desse grupo, mas também devido à complexidade e diversidade de refugiados existentes hoje. As categorias existentes de refugiados são:

a) Refugiados políticos: deixam seu país devido à perseguição política;

b) Refugiados religiosos: deixam seu país devido à perseguição religiosa;

c) Refugiados ambientais: deixam seu país devido à desastres ambientais;

d) Refugiados de guerras: deixam seu país devido à guerra;

e) Refugiados étnicos: deixam seu país devido à perseguição étnica. (MÉGDA, 2017, p. 14)

No caso analisado nesse artigo, os refugiados em questão podem ser enquadrados no conceito de refugiados políticos pois sofrem perseguição ao não aceitar o regime vigente em seu país de origem. Byer (2014) cita a definição de refugiado político como sendo o indivíduo que "se torna refugiado devido a sua relação com o governo existente (classe governante) (BEYER, 2014, p. 27). Entretanto, compreendese a complexidade em enquadrar todos os refugiados norte-coreanos somente nesse grupo sendo que não há formas de afirmar que todos em algum momento sofreram perseguição política. Ainda assim, considerando o regime atuante na Coreia do Norte e os relatos de perseguição política, o presente artigo irá considerar os refugiados como sendo políticos para fins de clareza na análise.

No que tange a importância dessa pesquisa, pode-se utilizar dos próprios dados providos pelo ACNUR que demostram que cerca de 67 milhões de pessoas nas últimas décadas deixaram seus locais de origem devido à violação de direitos humanos (ACNUR, 2018, p. 01). Nesse cenário se estabelece ainda mais a importância de organismos internacionais que atuem junto aos estados a fim de garantir os direitos desses indivíduos.

Dentro da ideia de globalização e da influência sofrida pelo Estado por parte de organizações externas a ele cabe uma breve análise da Teoria da Interdependência Complexa. Essa análise servirá como ferramenta na compreensão desse cenário onde Estados podem mutuamente se ajudar ou, Estados podem fazer parte de organizações internacionais que têm seu objeto de ação em um tema específico.

Joseph Nye e Robert Keohane, a partir da crise das ideias realistas, começaram a abordar a nova arena internacional de atuação que agora não mais se limitava a ação estatal. O Estado passaria a compartilhar essa arena com novos agentes que não possuíam poder suficiente para estabelecer políticas, 
mas sim, agentes que buscariam através da união dos Estados estabelecer e executar objetivos (RODRIGUES, 2014, p. 109).

Essa nova dinâmica internacional teve impulso após o fim da Guerra Fria onde o cenário até então mantido por polos de força foi substituído por uma nova conjunção e a atuação dos Estados se alterou a fim de se enquadrar a esse novo campo externo (RACY, ONUKI, 2002, p. 01). Logo, surge uma conjuntura onde os atores estatais não mais circulavam de forma individual, passando a compartilhar a esfera internacional com diversos outros atores governamentais e não governamentais de organização coletiva.

Keohane e Nye (2011), em seu trabalho, mencionam que a interdependência afeta as políticas em campo global também afetam o comportamento dos Estados. Entretanto, o Estado também atuaria de forma a influenciar nas questões de interdependência (KEOHANE, NYE, 2011, p. 05). Essa interdependência faz relação com o novo quadro presente na realidade globalizada, onde os estados passaram a construir uma rede entre si e com outros atores presentes nesse cenário.

A contribuição da pesquisa dos autores para o presente artigo é em relação ao reconhecimento de outros canais de relação entre os Estados, onde é reconhecido o papel de Organizações Internacionais no cenário global. Indo contra o pensamento do Realismo que detém uma visão centrada no Estado, a Teoria de Interdependência Complexa reconheceria as instituições que levam novos assuntos para a pauta de debates e ajudam a moldar as agendas Estatais no cenário internacional (KEOHANE, NYE, 2011, p. 20). Esse reconhecimento de outros organismos e atores se faz importante na análise das redes construídas entre esses diferentes agentes, possibilitando uma melhor leitura de suas ações coletivas e individuais.

Oliveira e Luvizotto (2011) apontam que esse novo cenário onde diversos atores passam a exercer influência e tomar decisões, ou seja, esse cenário multipolar contrário ao cenário vivenciado na Guerra Fria, é também um cenário que conduz aos atores a atuar de forma a visualizar além das fronteiras estatais (OLIVEIRA, LUVIZOTTO, 2011, p. 06). Junto a essas relações de interdependência entre diversos atores e o cenário multipolar concebido na era globalizada, tem-se a concepção de uma regime internacional. Os regimes internacionais atuam no papel de estabelecer um guia de procedimentos e regras a serem seguidos por estados e organizações sobre determinado tema. Esses regimes podem ser afetados pela estrutura de poder do sistema internacional, mas também exercem o papel de influenciar nas barganhas e decisões desse mesmo sistema (KEOHANE, ROBERTO, 2012, p. 16).

Um exemplo sobre o envolvimento entre Estado e agentes internacionais na modelagem de novas políticas e agendas pertinentes para a pesquisa aqui realizada é o ACNUR - Alto Comissariado das Nações Unidas para os Refugiados, abordado anteriormente nesse capítulo, e a Convenção de Genebra adotada pela Coreia do Sul. Ambos, ACNUR e a Convenção de Genebra, são importantes na compreensão 
da adoção de políticas voltadas para refugiados, assim como, do novo papel do Estado sul-coreano dentro desse tema.

Em relação a regimes e construção da agenda internacional, Oliveira e Luvizotto (2011) argumentam que o caráter de ausência de hierarquia entre temas de agenda em um cenário de interdependência complexa possibilita que questões como a debatida nesse artigo consigam lugar na arena de debate. Essa dinâmica propicia a criação de atores que representam temas específicos, o que se daria como uma globalização multidimensional (OLIVEIRA, LUVIZOTTO, 2011, p. 08). Sendo assim, o surgimento do ACNUR se estabelece como fruto dessa nova dinâmica global e o ambiente propício para a ascensão de diferentes temas na agenda governamental.

\section{OS REFUGIADOS NORTE-COREANOS EM NÚMEROS}

O movimento de indivíduos que partiam da Coreia do Norte rumo a Coreia do Sul teve início já no primeiro ano de divisão das Coreias. Até o ano de 1953, cerca de 10\% da população norte-coreana tinha deixado seu país (LANKOV, 2006, p. 108). Lee et al (2001) e Lankov (2004) apontam um agravamento nesse número devido às crises internas, a precariedade na saúde e diminuição na disponibilidade de alimentos para os norte-coreanos. Esses refugiados não se localizam somente na Coreia do Sul, mas com o intuito de cumprir com a análise aqui proposta, o artigo irá focar nos dados e programas relacionados aos refugiados em território sul-coreano.

Elaborado a partir dos dados providos pelo Ministro da Unificação da Coreia do Sul, o gráfico abaixo (gráfico 1) ilustra o avanço no número de refugiados no ano de 2005. Esse aumento permanece até o ano de 2011, quando o total de refugiados chega à 2,706. Porém, no ano seguinte é identifcada uma queda nesse número que se segue até o ano de 2016 quando ocorreu um breve crescimento, mas retomando a cair já no ano seguinte. 
Gráfico 1: Alteração no fluxo de refugiados norte-coreanos adentrando a Coreia do Sul.

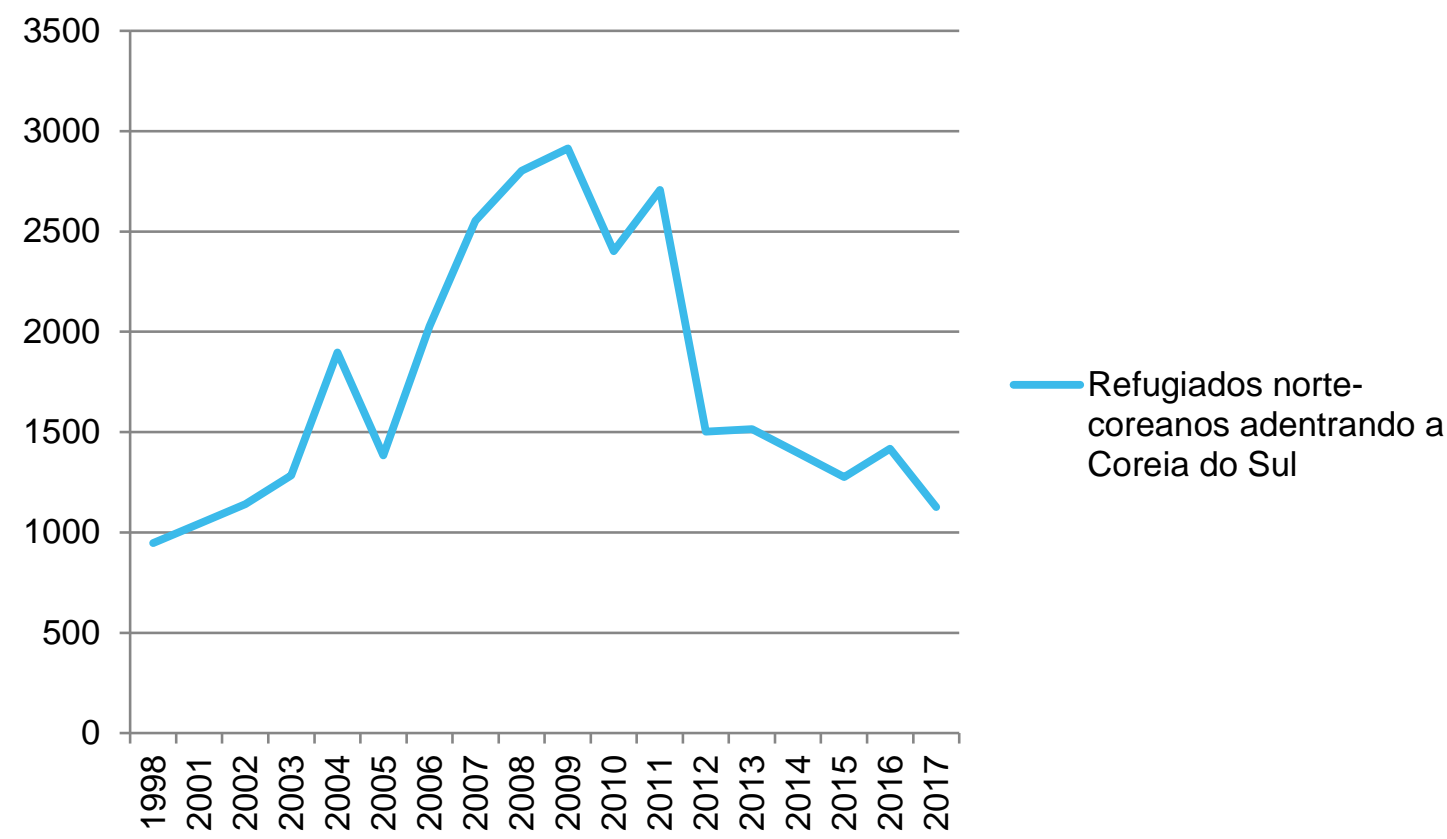

Fonte: Elaboração própria a partir dos dados do South Korean Ministry of Unification, 2018.

O gráfico abaixo (gráfico 2), construído a partir de informações disponibilizadas pelo Ministro da Unificação da Coreia do Sul, demonstra que os maiores grupos de norte-coreanos que deixam seu país pertencem à faixa etária de 20 a 39 anos. Nota-se que não é tão abundante a saída de membros mais jovens ou mais velhos a esse grupo etário. Entretanto, apesar de jovens, os norte-coreanos acabam enfrentando desafios ocasionados pelas necessidades que surgem durante essa idade. Compreende-se que os menores de 20 anos têm que se preocupar com seus estudos, enquanto que os maiores de 39 devem encontrar uma fonte de renda ao fim do auxílio governamental oferecido pelo governo sul-coreano. Têm-se, então, uma alta taxa de desistência escolar e relatos de refugiados norte-coreanos que não conseguem ser bemsucedidos profissionalmente em seu novo país (GO, 2014, p. 01). 
Gráfico 2: Faixa Etária dos refugiados norte-coreanos na Coreia do Sul.

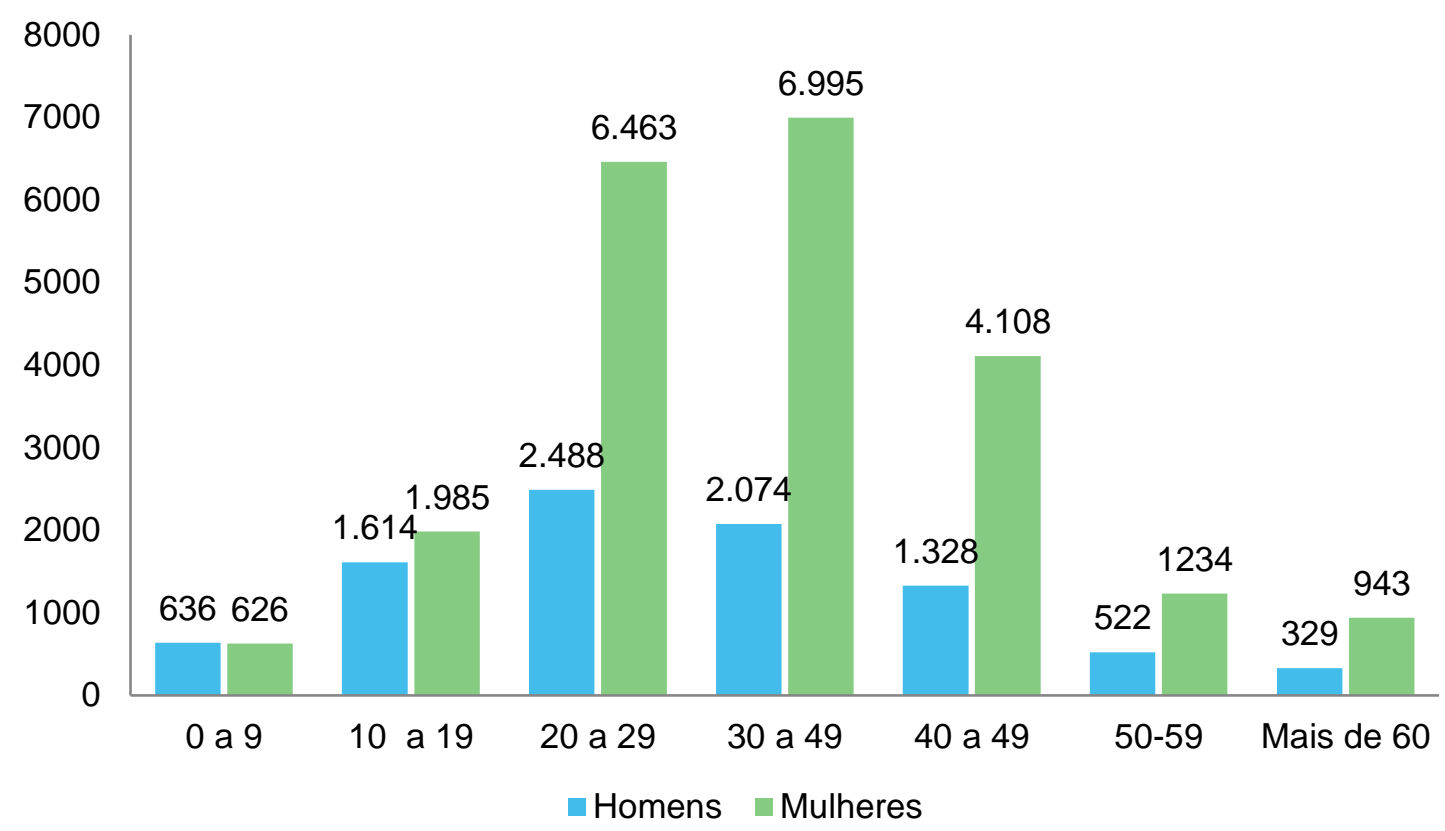

Fonte: Elaboração própria a partir de dados do South Korean Ministry of Unification, 2018.

Por um olhar mais econômico, a saída dessa faixa etária da Coreia do Norte pode se mostrar prejudicial em relação à produção interna no País, já que é uma idade de entrada no mercado de trabalho. Entretanto, isso poderia vir como auxílio para a Coreia do Sul ao ter que receber refugiados que pertencem a esse grupo.

Diversos Estados utilizam-se de políticas de atração de mão de obra externa a fim de auxiliar na produção interna do seu país, como é o caso do Japão devido à crise de natalidade (THE JAPAN TIMES, 2016). No caso específico da Coreia do Sul, tal "benefício" não se faz tão presente devido ao ambiente social no qual esses refugiados estarão inseridos, trazendo a tona o aspecto negativo de uma sociedade não preparada pelo seu governo para receber e aceitar a inserção desses refugiados dentro do seu meio social.

Números levantados pelo Ministro da Unificação da Coreia do Sul demonstram também que grande maioria dos refugiados norte-coreanos, quando ainda viviam em seu país, no que tange aos homens, eram de trabalhadores regulares. Já as mulheres norte-coreanas que se refugiaram na Coreia do Sul, em maioria, representavam o grupo de desempregados, conforme o gráfico 3 apresenta.

Esse dado é agravado quando considerado as informações apresentadas no gráfico 2, onde se verifica que a maior parte dos refugiados norte-coreanos são mulheres. Logo, nota-se o estabelecimento de um cenário onde maior parte dos refugiados consiste em mulheres que não atuavam profissionalmente 
antes de deixar seu país. Esses dados representam um grupo significativo de refugiados que enfrentariam dificuldades em conseguir estabelecer uma fonte de renda em um novo estado.

Gráfico 3: Refugiados norte-coreanos por enquadramento profissional.

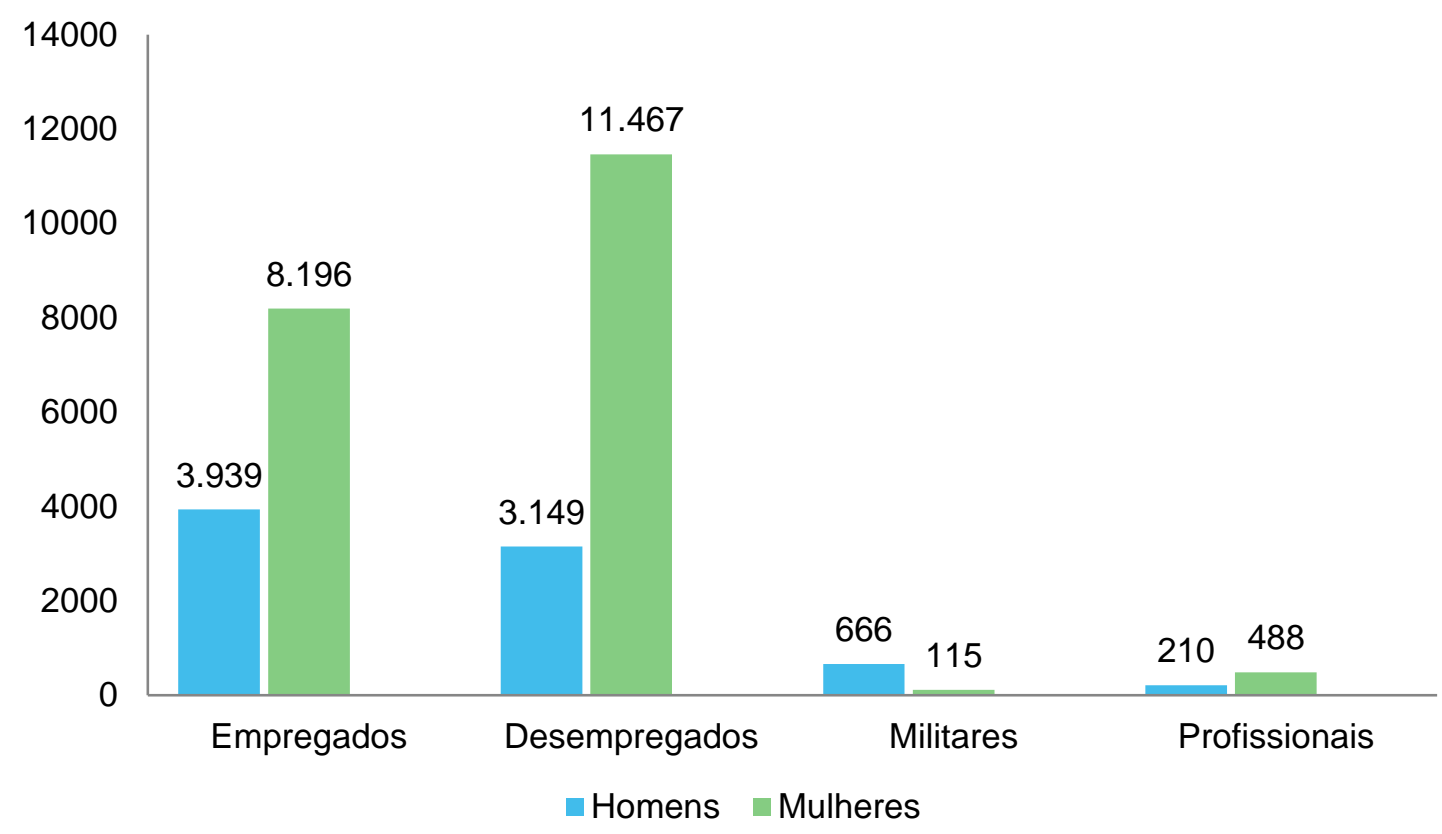

Fonte: Elaboração própria a partir de dados do South Korean Ministry of Unification, 2018.

Os números apresentados também podem ter ligação com a porcentagem de refugiados nortecoreanos com educação superior. Dados demonstram que 2,162 dos refugiados estiveram em uma universidade ou tiveram formação superior. Já em relação aos refugiados com nível educacional até o ensino médio o número total chega a 21,875 , cerca de 20 mil a mais do que o grupo anteriormente apresentado (SOUTH KOREA MINISTRY OF EDUCATION, 2018, p. 01).

Ainda que o número geral de refugiados esteja caindo em comparação com anos anteriores (Gráfico 1), os refugiados ainda buscam em terras sul-coreanas a chance de uma nova vida. Com base nos Direitos Humanos, nas políticas internacionais de abrigo aos refugiados e o caráter presente no cenário internacional de cooperação e interdependência, a Coreia do Sul ainda tem um importante papel a cumprir em relação a esse grupo que busca asilo em seu território.

\section{PROGRAMAS DE ACOLHIMENTO AOS REFUGIADOS NORTE-COREANOS E A SOCIEDADE SUL- COREANA}

No capítulo teórico anteriormente apresentado foram definidos alguns conceitos e apresentadas algumas caraterísticas sobre as políticas públicas. Compreendendo que o mesmo serviu de introdução ao 
tema, o presente capítulo buscará analisar as políticas públicas do estado sul-coreano voltadas para o acolhimento dos refugiados norte-coreanos.

A Lei de proteção e apoio aos refugiados norte-coreanos do governo da Coreia do Sul criou o Conselho Consultivo de Refugiados, presidido pelo vice-ministro e 25 membros de ministérios do governo sul-coreano. Esse conselho pode estender ou diminuir o prazo de proteção aos refugiados para garantir que os mesmos estejam seguros e sem riscos de vida. Durante esse período, os refugiados norte-coreanos recebem acesso gratuito a saúde e exames médicos. Após ter completado o processo de triagem, os refugiados vão para o Hanawŏn, centro estabelecido no ano de 1999. Hanawŏn é um centro moderno, com alta segurança e capacidade para acolher cerca de 750 pessoas em um período de treinamento de doze semanas (White Paper on Korean Unification, 2013, p. 229).

O centro Hanawŏn se concentra em quatro áreas para ajudar a realocação dos refugiados: saúde física e psicológica; estudos voltados para o comportamento e cultura da Coreia do Sul; suporte financeiro para viver inicialmente; e acompanhamento de carreira (WHITE PAPER ON KOREAN UNIFICATION, 2013, p. 230). A intenção é que os refugiados norte-coreanos aprendam sobre a cultura sul-coreana e se recuperem de traumas emocionais e físicos no período de três meses.

O processo de suporte para os refugiados norte-coreanos, em um todo, se da na seguinte forma: o refugiado deve solicitar proteção e transferência para a Coreia do Sul. Durante esse processo, ocorre a negociação com o país de origem do refugiado e a confirmação de sua identidade. Logo após a entrada do refugiado na Coreia do Sul há uma entrevista realizada pelo governo que, se bem-sucedida, permite que o refugiado seja encaminhando para Hanawŏn. Em seguida, discute-se sobre manter a proteção para o refugiado ou não. Caso positivo, o governo oferece um programa de 392 horas para auxiliar na adaptação social, acompanhamento psicológico para introduzir o refugiado na sociedade sul-coreana, e auxílio no período inicial em que o refugiado estará em contato com a sociedade. O refugiado recebe um suporte de cinco anos para adaptação em comunidade que inclui auxilio para moradia e saúde; suporte vocacional; suporte educacional e, agentes de proteção. O Estado também coloca os refugiados em contato com outras organizações, dessa vez não governamentais, capazes de oferecer ainda mais auxílios para a realocação e integração social desse grupo (MINISTRY OF UNIFICATION, 2012, p. 10).

Após completar o treinamento em Hanawŏn, os refugiados também podem receber assistência financeira, aulas de adaptação regional, suporte para conseguir emprego, educação e apoio médico. Os refugiados recebem um pagamento de 6 milhões de Won sul-coreano(cerca de 5 mil dólares), e caso participem das capacitações profissionais, encontrem um emprego ou adquiram certificados, podem receber um incentivo adicional de 24,4 milhões de Won sul coreanos (cerca de 22 mil dólares); os idosos, pais solteiros e deficientes físicos também recebem mais um adicional financeiro (STRANGERS AT HOME: NORTH KOREANS IN THE SOUTH, 2011, p. 15). 
Somado ao programa governamental ligado à Hanawon, há ainda a Korea Hana Foundation. Korea Hana Foundation é uma fundação sem fins lucrativos criada pelo Ministério da Unificação da Coreia do Sul que tem o princípio de "atuar na proteção e oferecer suporte para o estabelecimento dos desertores norte-coreanos" (tradução do autor). A Korea Hana Foundation trabalha sobre as diretrizes de auxiliar o refugiado a conseguir residência, trabalho, educação e integração social (KOREA HANA FOUNDATION, 2018, p. 01).

Sobre o programa de proteção ao emprego, o mesmo tem base legal no Artigo 17 e 17-2 da Lei de Apoio ao Reassentamento, e é uma forma de garantir subsídio para o trabalhador coreano e auxilia-lo a conseguir uma colocação no mercado de trabalho. O refugiado norte-coreano pode se candidatar para 0 programa a partir de dois anos após o seu emprego anterior, tendo um período de proteção que pode ser estendida em até um ano em caso de contratação pela mesma empresa. Para que o refugiado possa se candidatar para o programa de proteção ao emprego, ele deve entregar documentos que comprovem que o mesmo participou e completou treinamento vocacional e seu histórico de empregos em outros locais (a fim de verificar se ocorreram acidentes de trabalho, por exemplo). Os documentos são todos encaminhados para Hanawon que em até dez dias deve comunicar se o trabalhador é ou não elegível para o programa de proteção (MINISTRY OF UNIFICATION, 2012, p. 53).

Já o suporte educacional oferecido tem base legal no Artigo 24 da Lei de Suporte ao Reassentamento, e nos Artigos, 44, 45, 46 e 47 do Decreto de Execução da Lei e diretrizes de fiscalização. Para elegibilidade os refugiados devem ter no mínimo 24 anos e no máximo 34 anos. Os candidatos devem ter concluído o ensino médio mas não podem ter cursado um curso superior de quatro anos.

Em relação ao apoio financeiro, ele se divide conforme o grau de escolaridade: ensino médio e universidades nacionais e públicas - taxas de admissão, aula particular, taxa de apoio operacional da escola e dormitórios são isentos; universidades privadas - caso aprovado pelo Ministro da Unificação, recebe fundos para cobrir 50\% dos custos. A fim de garantir o suporte educacional o refugiado deve encaminhar um formulário de aplicação e o certificado de "receptor de proteção" emitido pelos oficiais de proteção (MINISTRY OF UNIFICATION, 2012, p. 54).

O governo sul-coreano também estabeleceu uma tabela para auxílio na transição escolar dos refugiados buscando adaptá-los ao formato educacional da Coreia do Sul. Medidas referentes a validação de diplomas também foram estabelecidas a fim de garantir que profissionais com formação superior conseguissem exercer sua profissão em seu novo território.

Apesar dos diversos programas de assistência na área da educação, profissionalização e outros campos, a maioria deles é limitado a um período máximo de cinco anos, com a crença de que esse seria o tempo necessário para a adaptação dos refugiados norte-coreanos nessa nova dinâmica social. Vê-se um 
Estado com políticas de acolhimento generosas e que se prolongam para setores importantes como educação e emprego. Não obstante, essas políticas se mostram otimistas demais ao não considerar problemas que poderiam surgir durante o período de adaptação social dos refugiados.

Um dos problemas identificados e ponto central desse artigo é a dificuldade de aceitação por parte da sua população sul-coreana em relação aos refugiados norte-coreanos devido a estigmas já enraizados dentro dessa sociedade. Muitos membros civis acreditam que os refugiados norte-coreanos estejam se aproveitando dos benefícios providos pelo governo, ou até mesmo, que são ingratos a ajuda recebida do estado sul-coreano. O aumento no número de refugiados, com o decorrer dos anos, agravou essa visão e tornou ainda mais difícil a alocação e introdução desses refugiados na sociedade, tornando visível a relação precária entre ambos os grupos ( $\mathrm{POHL}, 2006$, p. 02).

No capítulo teórico foi abordado como muitas vezes o Estado pode tomar decisões autônomas em relação às vontades de sua população. Nessa visão, nem sempre uma política pública irá seguir uma demanda social doméstica. No caso sul-coreano, essa pode ser considerada uma dinâmica de auxílio na compreensão da dificuldade de harmonia entre decisões políticas e a visão da sociedade sobre essas mesmas. Deve-se salientar que em momento algum se busca afirmar que a sociedade sul-coreana é contra aos direitos dos refugiados. O exercício aqui realizado é com o intuito de demonstrar como uma possível falha de comunicação entre governo e sociedade pode ocasionar na diminuição de sucesso de uma política implementada.

Gráfico 4: Questão aos refugigados norte-coreanos: "de que forma você é "ferido" pelos sul-coreanos?"

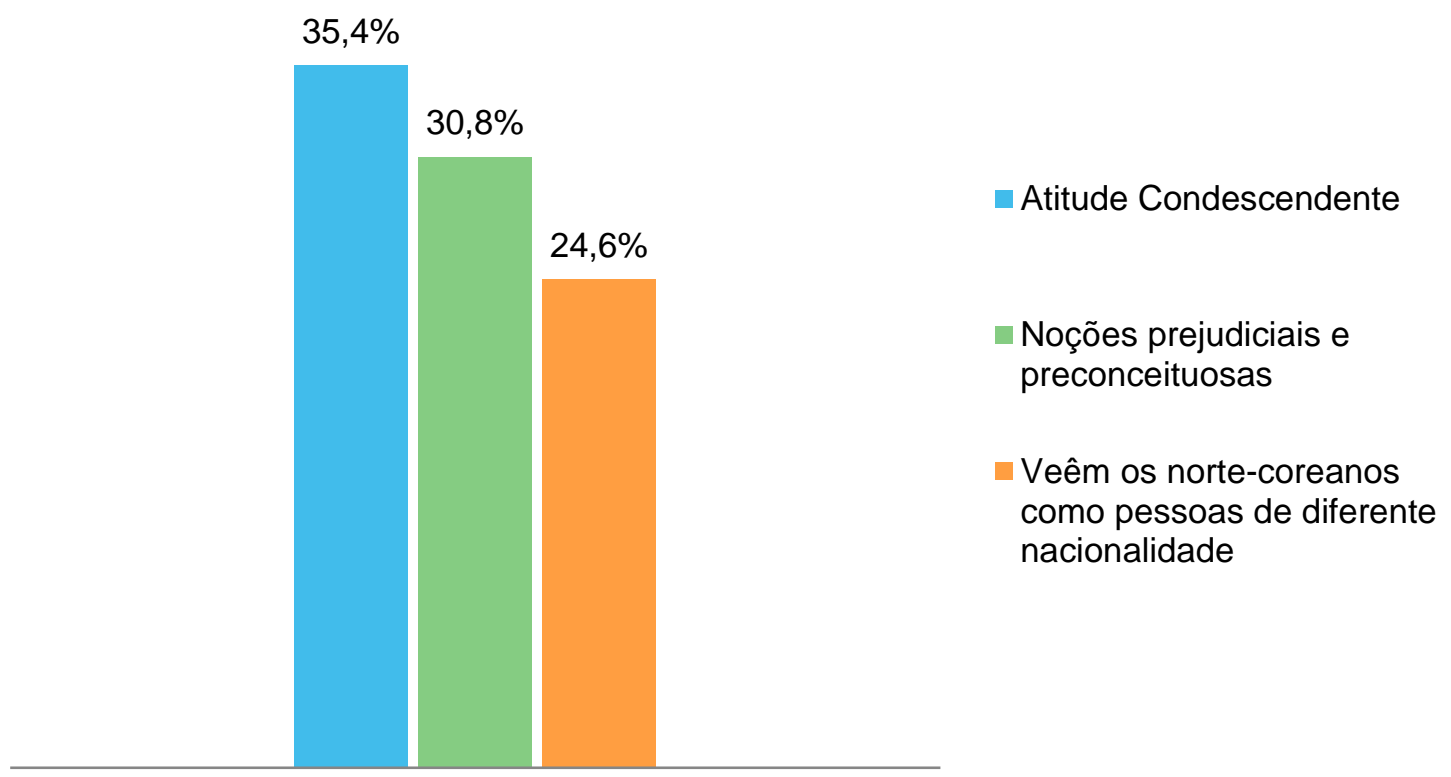

Fonte: Elaboração própria a partir de dados do South Korean Ministry of Unification, 2018. 
Ainda que amparados inicialmente por políticas públicas do governo sul-coreano, os refugiados norte-coreanos não conseguem deixar para trás sua identidade e caraterísticas. Devido a isso, são facilmente reconhecidos e alvos de pré-julgamentos, dificultando em sua convivência básica e até mesmo em relação a sua sobrevivência já que não há garantia de emprego $(\mathrm{OH}, 2010$, p. 05).

O gráfico 4 relata, a partir de dados colhidos no Ministro da Unificação da Coreia do Sul, que a visão dos sul-coreanos a respeito dos norte-coreanos como pertencendo a outra nacionalidade representa uma grande porcentagem entre os motivos dos quais os refugiados se sentem "feridos" na Coreia do Sul. O gráfico também apresenta que $30,8 \%$ dos refugiados são atingidos por atos ou comportamentos de preconceito.

Lee (2012) menciona em seu artigo a ausência de compreensão dos sul-coreanos em relação aos norte-coreanos como um dos fatores para o fracasso da adaptação dos refugiados na Coreia do Sul (LEE, 2012, p. 06). Nesse ponto, tornam-se fatores exclusivos para os refugiados norte-coreanos até mesmo sua aparência, que em uma sociedade que valoriza caraterísticas como altura e peso, os refugiados nortecoreanos acabam se destacando de maneira negativa já que seus corpos carregam as marcas de um regime em que o trabalho era em demasiado e a alimentação não tão abundante (AP, 2016, p. 04).

Um dos aspectos que exerce interferência na adaptação dos norte-coreanos na Coreia do Sul é o aspecto financeiro. A organização social em torno de um modelo capitalista sul-coreano criou um cenário onde o poder aquisitivo se tornou um fator importante sobre quem um indivíduo é - o que acaba por prejudicar os refugiados que não tem a concepção de acúmulo de uma sociedade baseada no capital. A dificuldade em conseguir emprego, mesmo com programas governamentais, leva a muitos dos refugiados norte-coreanos a recorrerem ao crime, conforme Lankov (2006) aponta. A dificuldade de aceitação e de integração por parte dos sul-coreanos acaba causando um considerável impacto na vida do refugiado norte-coreano (LANKOV, 2006, p. 124).

Pesquisas realizadas com refugiados norte-coreanos em terras sul-coreanos já comprovaram que grande porcentagem sente-se desconfortável devido à discriminação que sofrem (BYUN, 2016, p. 01), pelo seu vocabulário diferente, sotaque e aparência ( $\mathrm{POHL}, 2006$, p. 03). Conforme declaração de um nortecoreano citada por Lee (2012), os refugiados não têm suas opiniões ouvidas e por isto deveriam lutar contra si mesmos e suas caraterísticas norte-coreanas a fim de ter mais valor dentro da nova sociedade em que estão inseridos (LEE, 2012, p. 96).

Gráfico 5: Motivos que levam aos refugiados norte-coreanos a ficarem insatisfeitos com suas vidas na Coreia do Sul. 


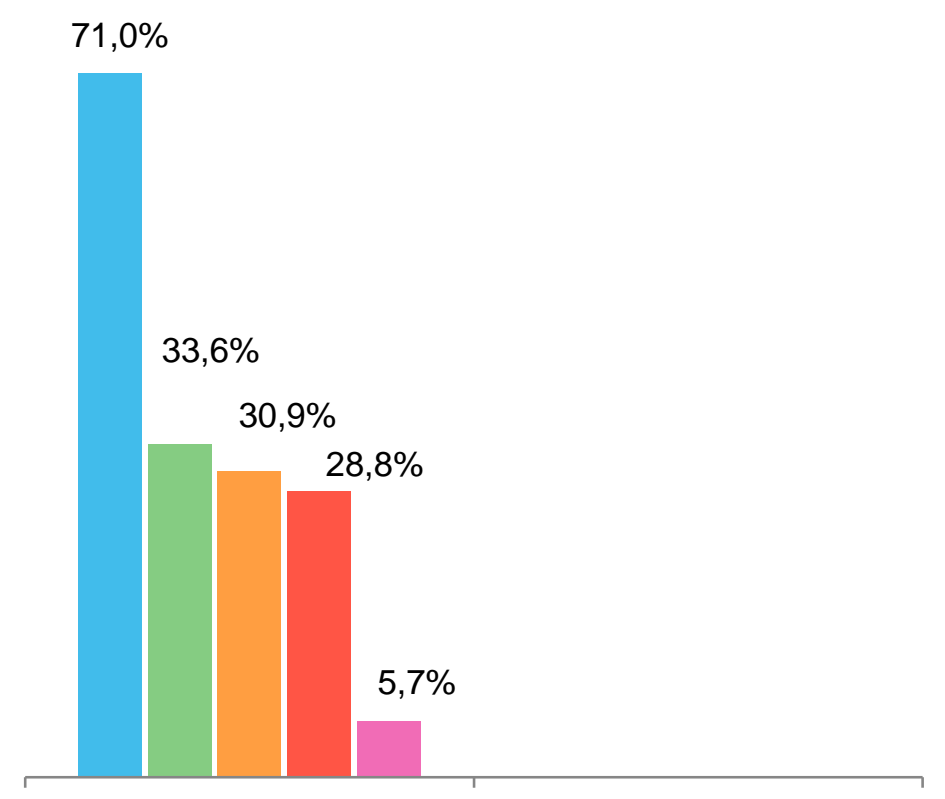

—ificuldades econômicas

- Discriminação contra refugiados norte-coreanos

- Diferença entre o que podem fazer e o que querem fazer

- Dificuldades com adaptação cultural

- Conflito com membros familiares

Fonte: Elaboração própria a partir de dados do South Korean Ministry of Unification, 2018.

No gráfico anteriormente apresentado (gráfico 5), nota-se que 33,6\% dos norte-coreanos identificam a discriminação sofrida como parte de sua insatisfação na Coreia do Sul. Ainda sobre os dados apresentados pelo Ministro da Unificação da Coreia do Sul, é possível perceber uma porcentagem considerável de norte-coreanos que enfretam dificuldade em relação a sua adaptação cultural, sendo essa mais um obstáculo no bem-estar dos membros desse grupo.

Jiyoon et al. (2015), em sua pesquisa, observaram que grande porcentagem da população sulcoreana mais jovem está perdendo o caráter de comum identidade quando se trata dos norte-coreanos. As questões de "valores" também foram as mais apontadas entre os jovens sul-coreanos como motivações para a concepção de distanciamento identitário com os norte-coreanos. Grande parte dessa visão pode ser interligada com a visão geral sobre a Coreia do Norte: a da militarização e armamento nuclear (JIYOON, et al., 2015. p. 10).

Ainda sobre a visão dos jovens sul-coreanos em relação aos norte-coreanos, identificou-se que quando se tratou de reunificação, esse grupo era favorável tendo em vista progressos econômicos que poderiam surgir e não questões sociais, o que difere de grupos de indivíduos mais velhos que veem na reunificação razões não econômicas (LEE, DENNEY, 2017, p. 05).

Tais aspectos identificados na camada jovem demonstram uma perda no processo identitário e uma ausência no reconhecimento dos norte-coreanos como tendo a mesma "origem", o que acaba por justificar as dificuldades dos refugiados norte-coreanos em relação a sua adaptação em um novo país. Em suma, é possível notar que há não somente a dificuldade de adaptação dos refugiados norte-coreanos em 
novas terras, mas também a dificuldade de adaptação dos sul-coreanos em relação a estes refugiados. É um grande choque cultural amparado por anos de um pré julgamento construído com poucas informações sobre aqueles que hoje deixam sua terra natal em busca de melhores condições de vida.

\section{CONSIDERAÇÕES FINAIS}

As dificuldades enfrentadas pelos norte-coreanos os forçaram a deixar seu território em busca de uma qualidade de vida diferente e que correspondesse a sua necessidade. $O$ aumento no número desses refugiados criou a necessidade do estabelecimento de políticas públicas que os recolhessem e auxiliassem a construir uma vida em um novo território.

O presente artigo teve como objetivo justamente analisar tais políticas, mais especificamente, as que foram implementadas pelo Estado sul-coreano. Foram identificas as principais medidas tomadas desde o processo de retirada do indivíduo de seu país de origem de forma segura, até auxílio financeiro para moradia e trabalho oferecidos para os refugiados. Entretanto, conforme hipótese levantada, os auxílios providos pelo governo sul-coreano falha ao não preparar sua própria sociedade para o acolhimento destes refugiados.

Conforme analisado, ainda há uma parcela dos sul-coreanos que tem dificuldade em aceitar os norte-coreanos devido às suas visíveis diferenças em níveis culturais e de comportamento, assim como, há a dificuldade de aceitar e compreender o auxílio financeiro provido pelo governo sul-coreano a estes refugiados.

Compreende-se que os Estados têm uma forma de organização social interna que pode diferir da organização presente em outros Estados. Em relação a isso, enquanto a Coreia do Sul vive uma realidade baseada na meritocracia priorizando os estudos e árduo trabalho, a Coreia do Norte vive uma realidade com menos foco no esforço individual para o auto crescimento, mas sim um esforço conjunto para o fortalecimento do Estado. Esse é somente um dos fatores que também influência na realocação dos refugiados norte-coreanos em território sul-coreano.

Conclui-se que os programas implementados não se articulam sobre um fator importante na realocação desses refugiados: os habitantes sul-coreanos. Ainda que os norte-coreanos passem por treinamentos e apoio psicológico para compreenderem e se adaptar a nova cultura, notou-se uma dificuldade por parte dos indivíduos sul-coreanos em aceitar esses refugiados como fazendo parte de sua sociedade. A ausência de um caráter identitário por parte dos sul-coreanos afeta a adaptação dos refugiados norte-coreanos e causa um impacto notável na organização social dos refugiados. 
Não obstante, ainda que o Estado sul-coreano precise avançar na disseminação de suas políticas públicas para refugiados dentro de sua própria sociedade, não se deve negar o papel fundamental que a Coreia do Sul exerce ao abrir as portas para os refugiados norte-coreanos. Ainda que careça de alguns avanços, as políticas aplicadas demonstram o anseio de um Estado em garantir os direitos básicos para aqueles que ali chegam, confirmando o caráter humanitário e de auxílio não só estatal, mas também em um contexto do cenário global. Conforme Dye (2013) menciona, a iniciativa em criar essas políticas já é por si mesma um ato simbólico que pode representar as "boas intenções" do Estado sul-coreano (DYE, 2013, p. 65).

* Artigo recebido em 31 mai 2018, aprovado em 10 set 2018.

\section{REFERENCIAS}

ACNUR BRASIL, Perguntas e respostas. 2018. Disponível em: < http://www.acnur.org/portugues/dadossobre-refugio/perguntas-e-respostas/> Acesso em: 04 de abril de 2018.

ACNUR. Convenção de 1951. 2018. Disponível em: < http://www.acnur.org/portugues/convencao-de1951/> Acesso em: 30 de maio de 2018.

ACNUR. Histórico. 2018. Disponível em: < http://www.acnur.org/portugues/historico/> Acesso em: 30 de maio de 2018.

AP, Some North Korean defectors wish they hadn't left in the first place, 2016. Disponivel em: <http://mashable.com/2016/04/04/north-korean-defector-regret/\#ZSKAd_tfKqqu> Acesso em: 25 de jun. de 2016.

BEYER, Gunter. The Political Refugee: 35 years later. International Migration Review,

Vol. 15, No. 1/2, pp. 26-34, 1981.

BYUN, Hannah, Embracing North Korean defectors, 2016, p. 01. Disponível em: <http://www.koreatimes.co.kr/www/news/nation/2016/06/181_205001.html> Acesso em: 25 de jun. de 2016.

DENTE, Bruno. Understanding Policy decisions. Springer, Politecnico di Milano, 2014.

DYE, Thomas R. Understanding Public Policy. 14ª ed. Harlow (England): Pearson Education Limited, 2013 
GEDDES, Barbara. Building "State" Autonomy in Brazil, 1930-1964. Comparative Politics, Vol. 22, No. 2, p. 217-235, 1990. Disponível em: < https://www.jstor.org/stable/422315?seq=1\#page_scan_tab_contents> Acesso em: 30 de agosto de 2018.

GO, Myong-Hyun, Resettling in South Korea: Challenges for Young North Korean Refugees, 2014, p. 01. Disponivel em: <http://en.asaninst.org/contents/resettling-in-south-korea-challenges-for-young-northkorean-refugees/> Acesso em: 25 de mar. de 2016.

HAMILTON, Nora. The Limits of State Autonomy: Post-Revolutionary Mexico. Princeton University Press, Reino Unido, 1982.

HILL, Michael. The Public Policy Process.4ํ. ed. Harlow (England): Pearson Education Limited, 2005.

ISHIYAMA, John, BREUNING, Marijke. 21st Century Political Science: A Reference Handbook, Sage Publications, Califórnia, 2011.

JIYOON, Kim.; et al. South Korean Attitudes toward North Korea and Reunification. Asan Public Opinion Report, The Asian Institute for Policy Studies, Seoul, 2015. Disponivel em: < https://thediplomat.com/wpcontent/uploads/2015/01/thediplomat_2015-01-29_13-53-09.pdf> Acesso em: 30 de maio de 2018.

KEOHANE, Robert O.; NYE, Joseph S. Power and Interdependence. Pearson, $4^{\mathrm{a}}$ ed., 2011.

KOREA HANA FOUNDATION. Who we are, 2018. Disponivel em: < https://www.koreahana.or.kr/eng/about/what_we_do.jsp> Acesso em: 30 de maio de 2018.

LANKOV, Andrei. Bitter Taste of Paradise: North Korean Refugees in South Korea. Journal of East Asian Studies, Cambridge University Press, vol. 6, ed. 1, 105-137, 2006. Disponível em: < https://www.cambridge.org/core/journals/journal-of-east-asian-studies/article/bitter-taste-of-paradisenorth-korean-refugees-in-south-korea/340C76A 5 EBB34DCB3985EFoE3F218077> Acesso em: 30 de maio de 2018.

LANKOV, Andrei. North Korean Refugees in Northeast China. Asian Survey, vol. 44, n. 6, 2004. Disponível em: <http://as.ucpress.edu/content/44/6/856.shor> Acesso em: 30 de agosto de 2018.

LEE, Hyeon Ju, May I call you North Korean? Negotiating differences and imagining the Nation in South Korea, 2012, p. $06 . \quad$ Disponível em: <https://scholarspace.manoa.hawaii.edu/bitstream/10125/100984/1/Lee_Hyeon_r.pdf> Acesso em: 25 de jun. de 2016.

LEE, Yunhwan. et al. Trauma Expeerience of North Korean refugees in China. American Journal of Preventive Medicine, vol. 20, n. 3, 2001. 
LEON, Peter. The stages approach to the policy process: what has it done? Where is it going? In: SABATIER, Paul A. Theory of the policy process. Theoretical lenses on public policy. Boulder (USA): Westview Press, 1999.

MASIERO, Gilmar, A Economia Coreana: Características Estruturais, 2000, p. 01. Disponível em: <http://www.pucsp.br/geap/artigos/art6.PDF> Acesso em: 05 de jun. de 2016.

MASIERO, Gilmar, As lições da Coréia do Sul, 2003, p. 02. Disponível em: <http://rae.fgv.br/sites/rae.fgv.br/files/artigos/1702.pdf> Acesso em: 05 de jun. de 2016.

MÉGDA, Yago S. O Panorama da Proteção Internacional dos Refugiados: A Problemática dos Refugiados Ambientais, o caso do Haiti e sua relação com o Brasil. Monografia -(Bacharelado em Relações Internacionais). Faculdade Damas da Instrução Cristã - FADIC, Recife, 2017.

MENY, Ives; THOENIG, Jean-Claude. Las políticas públicas.Trad. De Francisco Morata. Barcelona (España): Editorial Ariel S.A, 1992.

MILER, Linda Karen, Japanese colonialism in Korea 1910-1945: A document based essay exercise, 2007. Disponível em: <http://www.koreasociety.org/index2.php?option=com_docman\&task=doc_view\&gid=147> Acesso em: 25 de jun. de 2016.

OH, Kongdan, Embracing North Korean Defectors: The "Small Unification" of Korea, 2010, p. 05. Disponivel em: <https://www.brookings.edu/research/embracing-north-korean-defectors-the-smallunification-of-korea/> Acesso em: 25 de jun. de 2016.

OLIVEIRA, Marcelo F.; LUVIZOTTO, Caroline K. Cooperação técnica internacional: aportes teóricos. Revista Brasileira de Política Internacional, v. 54, n. 2, p. 05-21, 2011. Disponível em : <https://repositorio.unesp.br/handle/11449/10588> Acesso em: 30 de agosto de 2018.

POHL, Laura Elizabeth, Unexpected Lives: North Korean Refugees in South Korea, 2006. Disponível em: <http://laurapohl.com/project/unexpected-lives-north-korean-refugees-in-south-korea/> Acesso em: 25 de jun. de 2016.

RACY, Carlos J.; ONUKI, Janina. Globalização: perspectivas teóricas das relações internacionais. Revista de Economia e Relações Internacionais, vol. 1, n. 1, 2002. Disponível em: <http://www.faap.br/revista_faap/rel_internacionais/rel_01/racy.htm> Acesso em: 30 de agosto de 2018.

RODRIGUES, Noeli. Teoria da Interdependência: os conceitos de sensibilidade e vulnerabilidade nas Organizações Internacionais. Conjuntura Global, Vol.3, n.2, abr.jun., 2014, p. 107-116. Disponível em: $<$ http://www.humanas.ufpr.br/portal/conjunturaglobal/files/2015/01/Teoria-da-

Interdepend\%C3\%AAncia-Os-conceitos-de-sensibilidade-e-vulnerabilidade-nasorganiza\% 3 C $\% \mathrm{~A}_{7} \% \mathrm{C}_{3} \% \mathrm{~B}_{5}$ es-internacionais.pdf> Acesso em: 04 de abril de 2018. 
SECCHI, Leonardo. Políticas Públicas -Conceitos, Esquemas de Análise, Casos Práticos.São Paulo: Cengage Learning, 2012.

SKOCPOL, Theda. EVANS, Peter B. RUESCHEMEYER, Dietrich. Bringing the State back in. Cambridge University Press, 1985.

South Korean Ministry of Unification, 2018. Disponível em: < http://www.unikorea.go.kr/eng_unikorea/relations/statistics/defectors/> Acesso: 10 de Agosto de 2016.

SOUZA, Celina. Políticas Públicas: Conceitos, Tipologias e Sub-Áreas. Fundação Luís Eduardo Magalhães, 2002.

$<$ http://professor.pucgoias.edu.br/SiteDocente/admin/arquivosUpload/3843/material/o01-\%20A-

\%20POLITICAS\%20PUBLICAS.pdf> Acesso em: 04 de abril de 2018.

SOUZA, Celina. Políticas Públicas: uma revisão da literatura. Sociologias, porto alegre, n. 16, p. 20-45, 2006. Disponível em: <http://www.scielo.br/pdf/soc/n16/ao3n16> Acesso em: 30 de agosto de 2018.

Strangers at Home: North Koreans in the South Crisis Group Asia Report N²08, 14 July 2011.

THE JAPAN TIMES, Japan's need for foreign labor to get dire as 2050 nears, 2016. Disponível em: $<$ https://www.japantimes.co.jp/news/2017/12/31/national/japans-need-foreign-labor-get-dire-2050nears/\#.WsT2Tn8h3lU> Acesso em: 04 de abril de 2018.

THE PEOPLE'S CHALLENGES, 2016, p. 01. Disponível em: <http://www.libertyinnorthkorea.org/learn-nkchallenges/> Acesso em: 05 de jun. de 2016.

White Paper on Korean Unification. Crisis Group interview, MOU official, Seoul, 2011.

YU, Chai-Shin, The New History of Korean Civilization. iUniverse, Indiana, 2012. 